\title{
Properties and Rapid Consolidation of Nanocrystalline TiCo Compounds by High-Frequency Induction Heated Sintering
}

\author{
In-Jin Shon ${ }^{1, *}$, Hyun-Su Kang ${ }^{1}$, Chang-Yul Suh ${ }^{2}$, Wonbaek Kim² and Sung-Wook Cho ${ }^{2}$ \\ ${ }^{1}$ Division of Advanced Materials Engineering, Research Center of Advanced Materials Development, \\ Chonbuk National University, Jeonbuk 561-756, Korea \\ ${ }^{2}$ Minerals and Materials Processing Division, Korea Institute of Geoscience, Mining and Materials Resources, Daejeon, Korea
}

Nanopowders of TiCo were synthesized from Ti and Co by high energy ball milling. A highly dense nanostructured TiCo compounds were consolidated at low temperature by high-frequency induction heat sintering within $1 \mathrm{~min}$ of the mechanical synthesis of the powders (TiCo) and horizontal milled $\mathrm{Ti}+\mathrm{Co}$ powders under $100 \mathrm{MPa}$ pressure. This process allows very quick densification to near theoretical density and prohibits grain growth in nano-structured materials. The grain sizes of TiCo compounds were calculated. Finally, the average hardness values of nanostructured TiCo compounds were investigated. [doi:10.2320/matertrans.M2011253]

(Received August 18, 2011; Accepted September 16, 2011; Published November 2, 2011)

Keywords: TiCo, chemical synthesis, nanostructures, sintering, hardness

\section{Introduction}

Many intermetallic compounds exhibit the B2-type crystal structure, for example several aluminides (such as $\mathrm{NiAl}$, $\mathrm{FeAl}$, and CoAl) and titanides (such as NiTi, FeTi, and CoTi). ${ }^{1,2)}$ These B2-type aluminides and titanides generally show an attractive combination of physical and mechanical properties, including high melting point, excellent specific strength, good oxidation and corrosion resistance, and high phase stability. ${ }^{1,2}$ ) Therefore, some of them have been considered as promising materials for high-temperature structural application. ${ }^{1)}$ In addition, CoTi is of great interest because of shape memory properties. ${ }^{3)}$ However, as in the case of many such compounds, the current concern about CoTi focuses on their low fracture toughness below the ductile-brittle transition temperature. ${ }^{1)}$ To improve on the mechanical properties of these materials, the fabrication of nanostructured material has been found to be effective.

Nanocrystalline materials have potential as advanced engineering materials with improved physical and mechanical properties. ${ }^{45)}$ Recently, nanocrystalline powders have been developed by thermochemical and thermomechanical processes such as the spray conversion process (SCP), coprecipitation, high energy milling and electrical wire explosion. ${ }^{6-9)}$ However, the grain sizes of sintered materials are much larger than those of pre-sintered powders due to rapid grain growth that occurs during conventional sintering. Controlling grain growth during sintering is a key to the commercial success of nanostructured materials. Unconventional sintering techniques, including high-pressure densification, magnetic pulse compaction and shock densification, have been proposed to overcome the problem of grain growth. ${ }^{10-12)}$ However, these methods have failed to provide fast, reproducible techniques that yield large quantities of high density samples with nanostructured grains.

The high-frequency induction heated sintering (HFIHS) method recently emerged as an effective technique for

*Corresponding author, E-mail: ijshon@chonbuk.ac.kr sintering and consolidating high temperature materials. ${ }^{13,14)}$ HFIHS is similar to traditional hot-pressing, but the sample is heated by an induced electric current that flows through the sample and a die. This process increases the heating rate (up to $2000^{\circ} \mathrm{C} / \mathrm{min}$ ) to a degree much higher than that of traditional hot-press sintering.

The purpose of this work is to produce nanopowders of CoTi from $\mathrm{Co}+\mathrm{Ti}$ powders using high energy ball milling and dense nanocrystalline CoTi compound using highfrequency induction heated sintering. In our technique, compouds are formed within $1 \mathrm{~min}$ of the mechanical synthesis of the powders (CoTi) and horizontal milled Co+Ti powders using the induced current activated sintering method. Further, we evaluate the grain size and mechanical properties (hardness and fracture toughness) of the resulting materials.

\section{Experimental Procedures}

Powders of $99.5 \%$ pure Co $(<325$ mesh, Alfa, Aesar, USA) and $99.5 \%$ pure Ti ( -400 mesh, Sejong Materials Co., LTD, Korea) were used as starting materials. Co and Ti powders with molar ratio of $1: 1$ were mixed by two types of methods. First, the powders were milled in a high-energy ball mill, i.e., a Pulverisette- 5 planetary mill, at $250 \mathrm{rpm}$ and for $10 \mathrm{~h}$. Tungsten carbide balls $(8.5 \mathrm{~mm}$ in diameter) were used in a sealed cylindrical stainless steel vial under an argon atmosphere. The weight ratio of ball-to-powder was $30: 1$. Second, the powders were mixed in polyethylene bottles using zirconia balls with ethanol and were milled at a horizontal rotation velocity of $250 \mathrm{rpm}$ for $10 \mathrm{~h}$.

After milling, the mixed powders were placed in a graphite die (outside diameter, $40 \mathrm{~mm}$, inside diameter, $10 \mathrm{~mm}$, height, $40 \mathrm{~mm}$ ) and then introduced into the high-frequency induction heated sintering system made by Eltek in South Korea, shown schematically in reference. ${ }^{13,14)}$ The four major stages in the synthesis are as follows. The system was evacuated (stage 1). Next, a uniaxial pressure of $100 \mathrm{MPa}$ was applied (stage 2). A induced current was then activated 
and maintained to $1000^{\circ} \mathrm{C}$ with a heating rate of $1500^{\circ} \mathrm{C} / \mathrm{min}$ and was then turned off without a holding time (stage 3 ). At the end of the process, the sample was cooled to room temperature (stage 4). The process was carried out under a vacuum of $5.3 \mathrm{~Pa}$.

The relative densities of the sintered samples were measured by the Archimedes method. Microstructural information was obtained from product samples which were polished and etched using a solution of $\mathrm{HF}(10 \mathrm{vol} \%), \mathrm{HNO}_{3}$ ( $30 \mathrm{vol} \%)$ and $\mathrm{H}_{2} \mathrm{O}(60 \mathrm{vol} \%)$ for $1 \mathrm{~min}$ at room temperature. Compositional and micro structural analyses of the products were made through X-ray diffraction (XRD) and scanning electron microscopy (SEM) with energy dispersive X-ray analysis (EDAX). Vickers hardness was measured by performing indentations at a load of $10 \mathrm{~kg}$ and a dwell time of $15 \mathrm{~s}$ on the synthesized samples.

The crystallite sizes of TiCo were calculated by the formula suggested by Suryanarayana and Norton, ${ }^{15}$ )

$$
B_{\mathrm{r}}\left(B_{\text {crystalline }}+B_{\text {strain }}\right) \cos \theta=k \lambda / L+\eta \sin \theta
$$

where $B_{\mathrm{r}}$ is the full width at half-maximum (FWHM) of the diffraction peak after instrument correction, $B_{\text {crystalline }}$ and $B_{\text {strain }}$ are the FWHM caused by small crystallite size and internal stress, respectively, $k$ is constant (with a value of $0.9), \lambda$ is the wavelength of the $\mathrm{X}$-ray radiation, $L$ and $\eta$ are the crystallite size and internal strain, respectively, and $\theta$ is the Bragg angle. The parameters $B$ and $B_{\mathrm{r}}$ follow Cauchy's form with the relationship: $B=B_{\mathrm{r}}+B_{\mathrm{s}}$, where $B$ and $B_{\mathrm{s}}$ are the FWHM of the broadened Bragg peaks and the standard sample's Bragg peaks, respectively.

\section{Results and Discussion}

The X-ray diffraction pattern of horizontal milled powder and mechanically high energy ball milled powders from raw powders is shown in Figs. 1(a) and 1(b), respectively. TiCo was not synthesized during the horizontal rotation ball milling in ethanol, but synthesized during high energy ball milling. From the above results, the combustion reaction is completed during high energy ball milling. The full width at half-maximum (FWHM) of the diffraction peak is broad due to refinement of the powder and strain. Figure 2 shows an SEM image, X-ray mapping and EDS of the high-energy ball milled powder of Ti-Co. From the SEM image, the powders are agglomerated, while X-ray mapping at same point shows that $\mathrm{Ti}$ and $\mathrm{Co}$ are detected. Further, $\mathrm{Ti}$ and $\mathrm{Co}$ peaks are detected in EDS.

The XRD patterns of the TiCo powder and Ti-Co powder milled using high-energy ball and horizontal ball, respectively, heated to $1000^{\circ} \mathrm{C}$ are shown in Fig. 3. In Fig. 3(b), Only TiCo peaks are detected. In Fig. 3(a), TiCo and $\mathrm{TiCo}_{2}$ peaks are detected. Based on the X-ray patterns of Fig. 1(a) and Fig. 3(a), TiCo was synthesized from horizontal milled powder of $\mathrm{Ti}$ and Co during heating. The presence of $\mathrm{TiCo}_{2}$ in the sample suggests a Ti deficiency. It is believed that this observation is related to the entrapped oxygen in the pores of the interior portion of the sample during pressing or possibly to the slight oxidation of Ti during heating. And it is reported that the oxidation of Co nanoparticle did not occur in sintering. ${ }^{16)}$

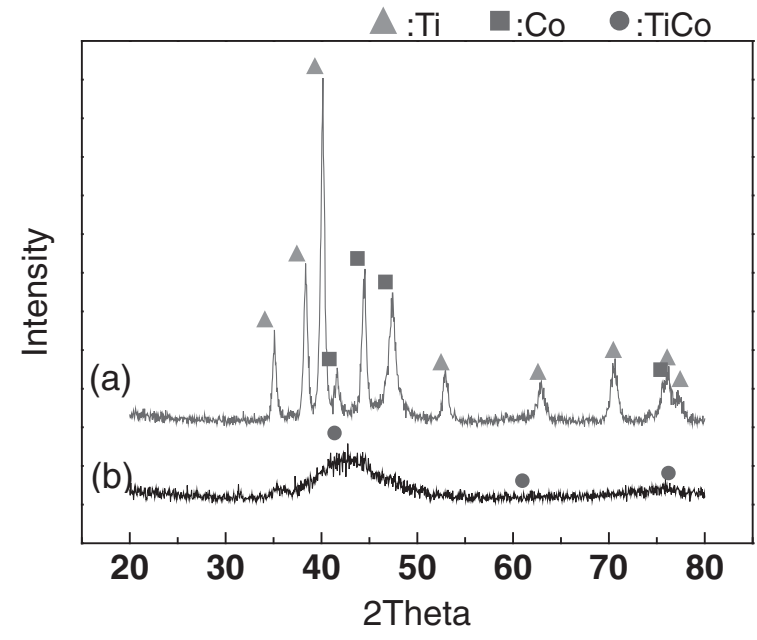

Fig. 1 XRD patterns of the milled powder by (a) horizontally milling and (b) mechanically milling.

Figure 4 shows a plot of $B_{\mathrm{r}} \cos \theta$ versus $\sin \theta$, used to calculate the crystallite size of TiCo. The structure parameters, i.e., the average crystallite sizes of TiCo sintered using horizontal ball milled powders and high-energy ball milled powders, are $30 \mathrm{~nm}$ and $20 \mathrm{~nm}$, respectively. Further, the relative density of the TiCo compound were $99.5 \%$. FE-SEM images of TiCo compound sintered at $1000^{\circ} \mathrm{C}$ from horizontal milled powders and high energy ball milled powders are shown in Fig. 5. As shown, the compounds consist of nano-crystallites.

Composites made up of nano-crystallites and high TiCo densities were obtained at low temperatures for two reasons. First, the small crystallite size is attributed to the high heating rate and relatively short powder exposure to high temperature. The types of current (resistive or inductive) used in sintering and/or synthesis have been the focus of several attempts to explain enhanced sintering and improved product characteristics. The role of current is explained in terms of fast Joule heating, the presence of plasma in pores separating powder particles, and the intrinsic contribution of current to mass transport. ${ }^{17-20)}$ Second, applying pressure during initial sintering adds another term to the surface energy driving force such that the total driving force, $F_{\mathrm{D}}$, may be expressed as: ${ }^{21)}$

$$
F_{\mathrm{D}}=\gamma+\left(P_{\mathrm{a}} r / \pi\right)
$$

where $\gamma$ is the surface energy, $P_{\mathrm{a}}$ is the applied pressure, and $r$ is the particle radius. The effect of pressure on the densification of nanometric, stabilized $\mathrm{ZrO}_{2}$ during high frequency-induced heated sintering was investigated by Shon et al. $^{22)}$ The relative density increased significantly as pressure increased from 60 to $100 \mathrm{MPa}$ for sintering at $1000^{\circ} \mathrm{C}$.

Vickers hardness measurements were made on polished sections of the TiCo composite using a $10 \mathrm{~kg}_{\mathrm{f}}$ load and $15 \mathrm{~s}$ dwell time. The hardness values of the TiCo compounds sintered at $1000^{\circ} \mathrm{C}$ from horizontal milled powders and high energy ball milled powders were calculated as 610 , $750 \mathrm{~kg} / \mathrm{mm}^{2}$, respectively. These values represent an average of five measurements each. Cracks did not produce around the indent. 
(a)

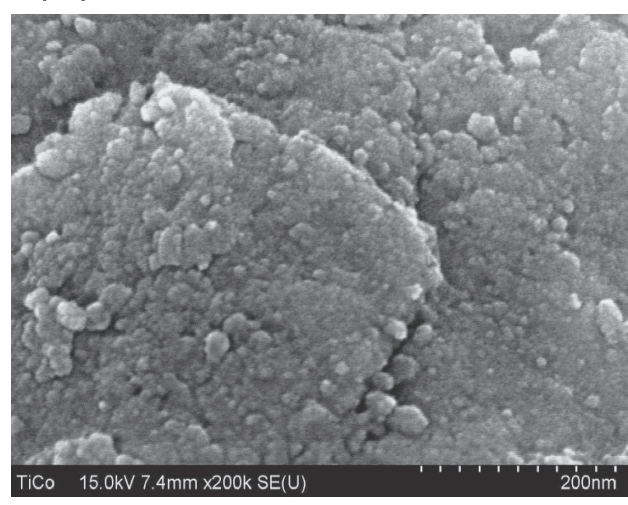

(c)

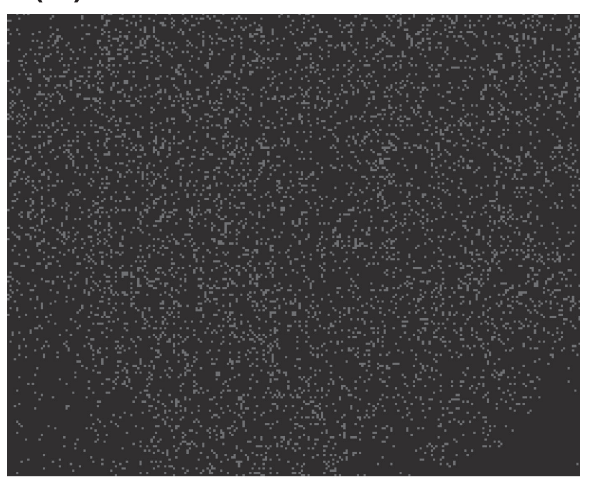

(d)

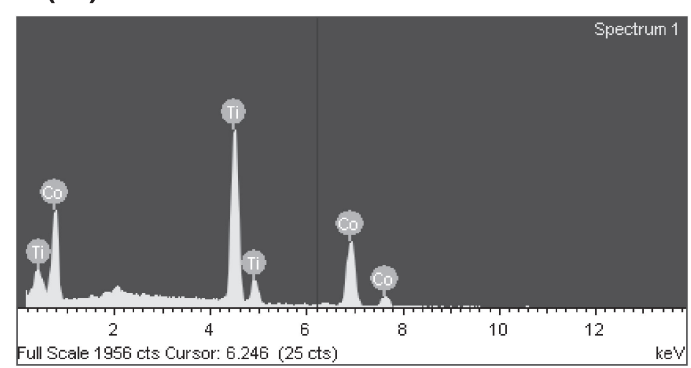

Coka1 (b)

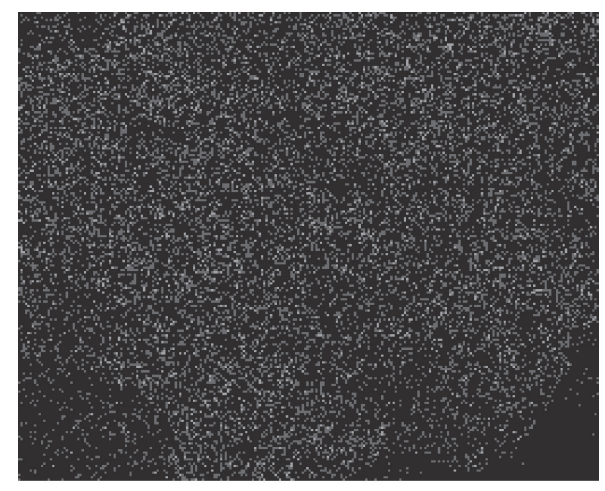

Tika1

Fig. 2 SEM image, X-ray mapping and EDS of high energy ball milled powders of Ti-Co.

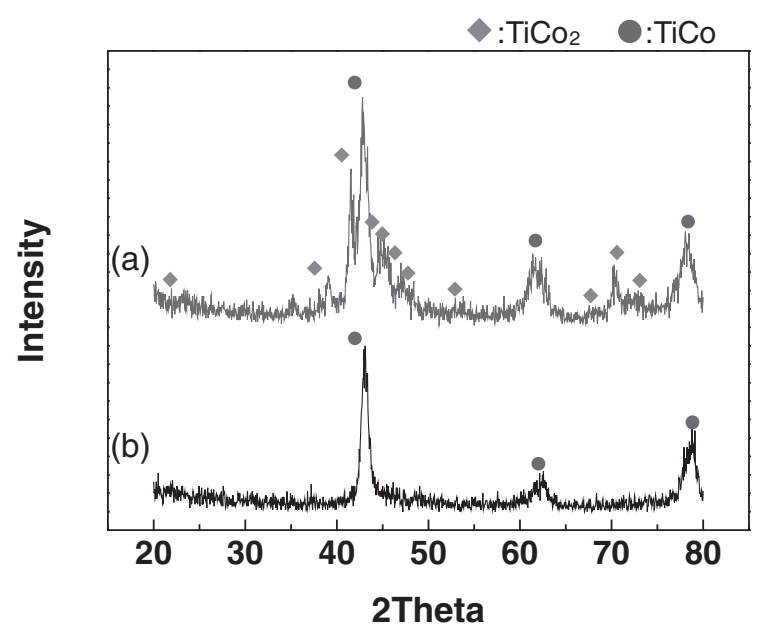

Fig. 3 XRD patterns of TiCo compounds sintered from (a) horizontal milled powders and (b) high energy ball milled powders.

Kaneno et al. ${ }^{1)}$ investigated properties of TiCo which was arc-melted, hot-rolled at $1273 \mathrm{~K}$ and then recrystallized at $1323 \mathrm{~K}$. The hardness and grain size of TiCo are reported as $235 \mathrm{~kg} / \mathrm{mm}^{2}$ and about $100 \mu \mathrm{m}$, respectively. The hardness of the TiCo compound is lower than that of TiCo sintered from horizontal milled powders and high energy ball milled powders due to large grain.
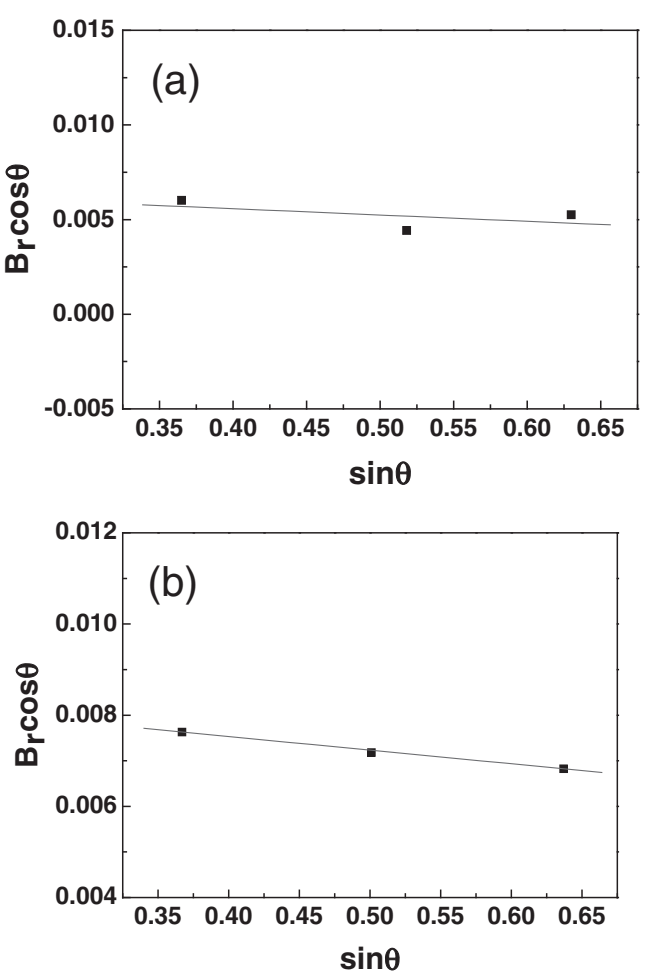

Fig. 4 Plot of $B_{\mathrm{r}} \cos \theta$ versus $\sin \theta$ of TiCo compounds sintered from (a) horizontal milled powders and (b) high energy ball milled powders. 

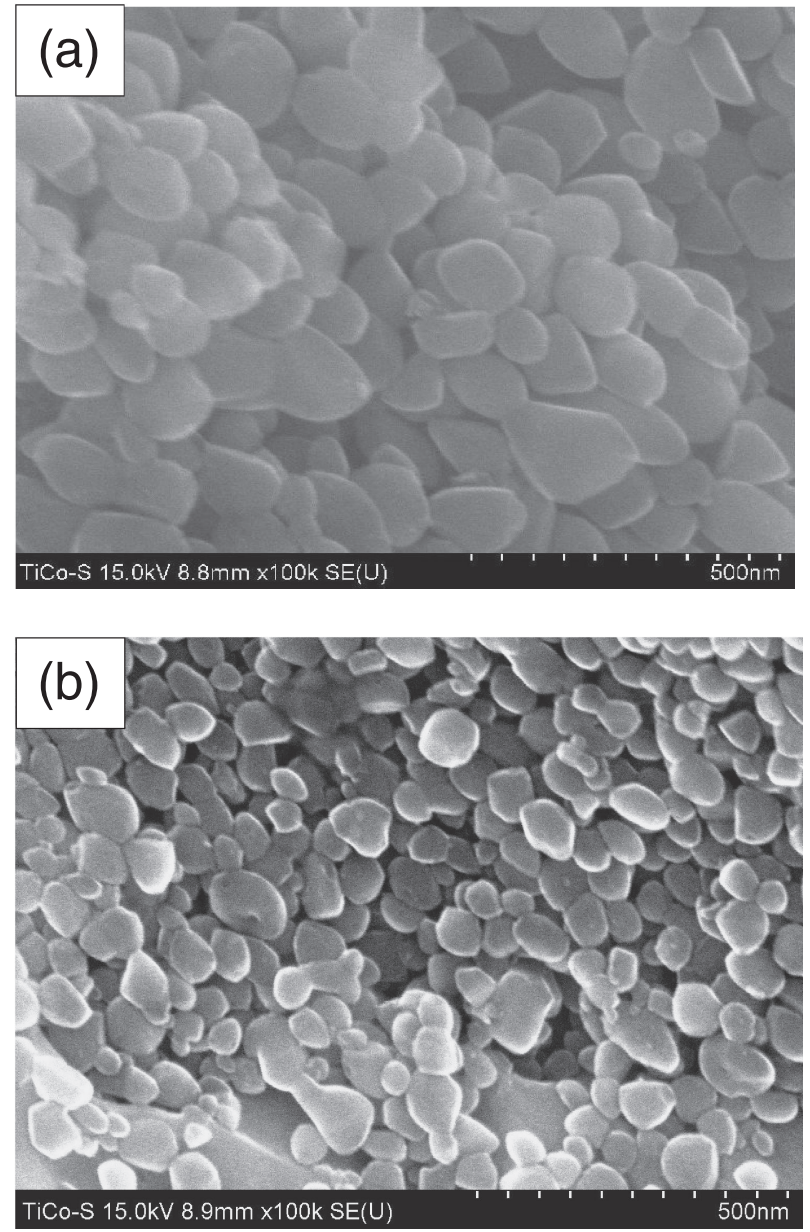

Fig. 5 FE-SEM images of TiCo compounds sintered from (a) horizontal milled powders and (b) high energy ball milled powders.

\section{Conclusions}

Nanopowders of TiCo were synthesized from Ti and Co by high energy ball milling. Using the high-frequency induction heated sintering method, the densification of nanostructured TiCo compound was accomplished using mechanically synthesized powders and horizontal milled powders within $1 \mathrm{~min}$. The average hardness values and crystallite sizes obtained from mechanically synthesized powders and horizontal milled powders were $750,610 \mathrm{~kg} / \mathrm{mm}^{2}$ and $20,30 \mathrm{~nm}$, respectively. The hardnesses of the TiCo compounds are higher than that of TiCo which was arc-melted, hot-rolled at
$1273 \mathrm{~K}$ and then recrystallized at $1323 \mathrm{~K}$ due to refinement of grain size.

\section{Acknowledgments}

This study was supported by a grant from basic research project of Korea Institute of Geoscience and Mineral Resources.

\section{REFERENCES}

1) Y. Kaneno, T. Takasugi and S. Hanada: Mater. Sci. Eng. A 302 (2001) 215-221.

2) Y. Terada, K. Ohkubo, K. Nakagawa, T. Mohri and T. Suzuki: Intermetallics 3 (1995) 347-355.

3) W. L. Frankhouser, K. W. Brendly, M. C. Kieszek and S. T. Sullivan: Gasless Combustion Synthesis of Refractory Compounds, (Noyes Publication, Park Ridge, NJ, USA, 1985).

4) M. S. El-Eskandarany: J. Alloy. Compd. 305 (2000) 225-238.

5) L. Fu, L. H. Cao and Y. S. Fan: Scr. Mater. 44 (2001) 1061-1068.

6) Z. Fang and J. W. Eason: Int. J. Refract. Met. Hard Mater. 13 (1995) 297-303.

7) A. I. Y. Tok, L. H. Luo and F. Y. C. Boey: Mater. Sci. Eng. A 383 (2004) 229-234.

8) I. J. Shon, D. K. Kim, K. T. Lee and K. S. Nam: Met. Mater. Int. 14 (2008) 593-598.

9) W. Kim, J. S. Park, C. Y. Suh, S. W. Chon, S. Lee and I. J. Shon: Mater. Trans. 50 (2009) 2897-2899.

10) S. C. Liao, W. E. Mayo and K. D. Pae: Acta Mater. 45 (1997) 40274032 .

11) Z. Q. Jin, C. Rockett, J. P. Liu, K. Hokamoto and N. N. Thadhani: Mater. Sci. Forum 465-466 (2004) 93-97.

12) V. Ivanov, S. Paranin, V. Khrustov, A. Medvedev and A. Shtol'ts: Key Eng. Mater. 206-213 (2002) 377-381.

13) H. C. Kim, I. J. Shon, J. K. Yoon and J. M. Doh: Met. Mater. Int. 12 (2006) 141-147.

14) H. C. Kim, I. J. Shon, I. K. Jeong and I. Y. Ko: Met. Mater. Int. 12 (2006) 393-398.

15) C. Suryanarayana and M. Grant Norton: X-ray Diffraction A Practical Approach, (Plenum Press, New York, 1998).

16) Y. Sakka: J. Less-Common Metals 168 (1991) 277-287.

17) Z. Shen, M. Johnsson, Z. Zhao and M. Nygren: J. Am. Ceram. Soc. 85 (2002) 1921-1927.

18) J. E. Garay, U. Anselmi-Tamburini, Z. A. Munir, S. C. Glade and P. Asoka-Kumar: Appl. Phys. Lett. 85 (2004) 573-575.

19) J. R. Friedman, J. E. Garay, U. Anselmi-Tamburini and Z. A. Munir: Intermetallics 12 (2004) 589-597.

20) J. E. Garay, U. Anselmi-Tamburini and Z. A. Munir: Acta Mater. 51 (2003) 4487-4495.

21) R. L. Coble: J. Appl. Phys. 41 (1970) 4798-4802.

22) H. Cheol, I. J. Shon, I. K. Jeong and I. Y. Ko: Met. Mater. Int. 12 (2006) 393-398. 